\title{
ELEVATED LIVER ENZYMES IN PATIENTS WITH ACUTE CHOLECYSTITIS
}

\section{Dr. Pavan Kumar*}

Dr. S. V. Eswaran
Post Graduate, Department Of General surgery. NMC Nellore.

${ }^{*}$ Corresponding Author

Post Graduate, Department Of General surgery, NMC Nellore.

\section{KEYWORDS :}

\section{INTRODUCTION}

Liver damage in patients with gallstones is thought to be the result of chronic extra hepatic large bile duct obstruction with or without repeated episodes of cholangitis and may ultimately progress to secondary biliary cirrhosis (11).Hepatic viral infection is by no means the only cause of acute hepatitis (Chen etal, 2007). One sitting in which there may be an acute inflammation of the liver parenchyma is the presence of common bile duct stones and cholangitis.

Hepatocellular injury is identified by increase in serum aspartate aminotransferase (AST) and alanine aminotrasferase (ALT). The severity of such injury may be reflected in decreased hepatic production of certain products such as albumin and clotting factors. Inflammation or damage to the biliary tract is signaled by an increase in alkaline phosphatase (ALK-P) which is sometimes confirmed by measurement of gamma-glutamyl-traspeptidase (GGT).

Serum bilirubin levels may be elevated in both biliary tract and hepatocellular diseases (5).

patients with acute or chronic cholecystitis and some patients with reactive hepatitis also has acute inflammatory cells in portal tracts and this correlated with acute inflammation in the gallbladder (21).

\section{MATERIALS AND METHODS}

This is a retrospective study. We reviewed the medical records of patients admitted to our Hospital, from January 2015 to march 2020 who underwent cholecystectomies for gallbladder stones associated with acute. Which includes 231 patients with acute cholecystitis, 94 males and 137 females with mean age 40.42 (range from 26 to 60 years). The exclusion criteria for our patients include those who had undergone ERCP or MRCP, those with sonographic evidence of a common bile duct disorders, patients with viral hepatitis( hepatitis $A$, hepatitis B or, hepatitis $\mathrm{C}$ ), alcoholic liver disease, drug related hepatitis, metabolic liver disease, autoimmune hepatitis and patients with pancreatitis All patients were subjected to liver function tests in the form of aspartate aminotrasferase( AST), alanine aminotrasferase( ALT), alkaline phosphatase( ALK-P), gammaglutamyl-transpeptidase( GGT ), Total and direct bilirubin prior to and four weeks post-operatively. The peripheral leucocyte count was also recorded. All patients had stones in the gallbladder as demonstrated by abdominal sonography. All specimens were submitted for histopathological examinations and diagnosed as either simple or gangrenous cholecystitis.

\section{RESULTS}

231 patients who had an acute cholecystitis without evidence of common bile duct stones and who underwent urgent Cholecystectomy. The gallbladder histology revealed gangrenous cholecystitis in 47 patients (20.4\%). The only significant differences between that group and the 184 patients with simple cholecystitis were a higher bilirubin level (P0.001) and WBC (P 0.018). (table2).
At all, there were a significant differences between the levels of AST, ALK-P, GGT pre- and post-Cholecystectomy $(\mathrm{P}<0.001)$, but the levels of ALT, Total and direct bilirubin showed no significant differences before and after Cholecystectomy

Table.1 Liver Function Tests Acute Cholecystits

\begin{tabular}{|l|l|l|}
\hline Variables & Range & Mean +/- SD \\
\hline Age & $26-60$ & $40.42 \pm 8.85$ \\
\hline AST & $15-900$ & $118 \pm 159.57$ \\
\hline ALT & $16-412$ & $126.64 \pm 81.81$ \\
\hline ALK-P & $65-250$ & $140.57 \pm 44.33$ \\
\hline GGT & $39-130$ & $69.46 \pm 23.61$ \\
\hline T. BILIRUBIN & $0.8-2.7$ & $1.55 \pm 0.5$ \\
\hline D. BILIRUBIN & $0.0-1.2$ & $0.67 \pm 0.39$ \\
\hline TLC & $5.2-20.1$ & $12.83 \pm 2.83$ \\
\hline Sex M/F & $94: 137$ & \\
\hline
\end{tabular}

Table 2. Liver function tests and TLC in Patients with acute simple and acute gangrenous cholecystitis

\begin{tabular}{|l|l|l|l|}
\hline Variables & $\begin{array}{l}\text { Acute simple } \\
\text { cholecystitis }\end{array}$ & $\begin{array}{l}\text { Acute gangrenous } \\
\text { cholecystitis }\end{array}$ & P value \\
\hline AST & $116.1 \pm 149.75$ & $119.2 \pm 167.1$ & 0.12 \\
\hline ALT & $125.2 \pm 79.8$ & $128.7 \pm 80.8$ & 0.12 \\
\hline ALK-P & $138.14 \pm 41.3$ & $141.2 \pm 43.1$ & 0.18 \\
\hline GGT & $68.5 \pm 22.1$ & $70.1 \pm 24.2$ & 0.16 \\
\hline T. bilirubin & $1.48 \pm 0.48$ & $1.9 \pm 0.61$ & 0.001 \\
\hline D. bilirubin & $0.65 \pm 0.3$ & $0.69 \pm 0.6$ & 0.1 \\
\hline TLC & $12.08 \pm 2.36$ & $17.12 \pm 2.91$ & 0.018 \\
\hline
\end{tabular}

\section{DISCUSSION}

Cholecystitis is inflammation of the gallbladder that develops over hours, usually because a gallstone obstructs the cystic duct, if it develops slowly overtime it is called chronic cholecystitis. Symptoms include right upper quadrant pain and tenderness, sometimes accompanied by fever, chills nausea and vomiting $(13,17)$.

Acute cholecystitis is the most common complication of cholelithiasis. Conversely, about $95 \%$ of patients with acute cholecystitis have cholelithiasis. When a stone becomes impacted in the cystic duct and persistently obstructs it, acute inflammation results. Bile stasis triggers release of liver enzymes e.g., serum 5 NT, ALP, AST, ALT along with serum bilirubin level. The gallstones blocks fluid from passing out of the gallbladder. This results in an irritated and swollen gallbladder (2).

Liver function test has been used as a routine preoperative evaluation for the gallbladder surgery as a tool to check for functional status of the liver. In a study done by Geraghty and Goldin in 1994, he stated that there is a high proportion (66\%) of patients with gallstones and cholecystitis had abnormal liver histology. The most common findings were non-specific reactive hepatitis and large droplet fatty change. Cholecystitis should be regarded as a cause of reactive hepatitis. Some patients with reactive hepatitis also had acute inflammatory 
cells in portal tracts and this correlates with acute inflammation in the gallbladder (11).

The origins of alkaline phosphatase are two, the liver and bone. If the serum alkaline phosphatase is persistently elevated for a long period of time, it suggests prolonged cholestasis (10). In our study, the serum alkaline phosphatase was significantly elevated in patients with acute calcular cholecystitis with the highest level up to $250 \mathrm{IU} / \mathrm{L}$. This correlated with a study done by Thapa etal in 2010; he stated that, the serum level of ALK-P was raised in patients with acute cholecystitis by $1.69+0.118$ fold with significant statistical difference. But if serum level of ALK-P was more than 2.5 folds higher than normal value, we could predict common bile duct stones. However, ALK-P is a non-specific indicator of cholestatic liver disease because of its multiple sources like bone, placenta beside its production from the biliary canalicular membrane hence together with determination of more specific enzymes such as Gamma-glutamyl transpeptidase and $5^{\prime}$ Nucleotidase had to be raised for inclusion criteria to minimize this error $(20,23)$. In our patients, the serum levels of gammaglutamyl- transpeptidase (GGT) were significantly elevated in patients with acute cholecystitis with the highest level was 130 IU/L . In a study done by Peng and his collageous, the serum level of GGT was more than 90 $\mathrm{IU} / \mathrm{l}$ is considered being high risk to have stone in common bile duct though not statistically significant and supported by many series.

The serum levels of AST and ALT were elevated in our patients, but the serum AST was significantly elevated if compared to the serum level of ALT. This indicates that, there is some degree of hepatocellular injury in patients with cholecystitis especially of the acute form and this injury is transient and returned to normal after cholecystectomy by about 30 days as in our patients.

In a study done by Chen-Wang and his collageous, he stated that hepatocellular injury (diagnosed clinically by elevation of aminotrasferase and bilirubin levels) was common. The incidence was higher and the aminotrasferase elevations were more marked in those with stones, but some patients without CBD stones also had a degree of hepatocellular injury. In most patients, the AST, ALT, and bilirubin levels had almost returned to normal within two weeks to one month after cholecystectomy. This hepatocellular injury, even showing relatively high serum levels of aminotrasferases and bilirubin should not be an obstacle to preparation of these patients for surgical intervention. This injury is transient and mild and will resolve spontaneously as expected, provided that the diseased gallbladder is removed (5).

Jaundice is not a rare manifestation of gallbladder disease without evidence of CBD stones. Thus, in our patients the mean total bilirubin was $1.35 \mathrm{mg} / \mathrm{dl}$ with the highest level was $2.7 \mathrm{mg} / \mathrm{dl}$ especially in patients with acute calcular cholecystitis. These results were correlated with the results done by chang and his collageous (3).

Twenty five percent of patients with acute calcular cholecystitis had a serum bilirubin level between 2 to $5 \mathrm{mg} / \mathrm{dl}$ with no CBD abnormality. Also, over one third of patients with acalculous cholecystitis had an elevated bilirubin level with a normal CBD ( 14). In some studies, there is a correlation between the bilirubin concentration and lipid peroxidation in cases of biliary tract diseases, with the presence of interaction between free radical reactions, gallbladder formation and the degree of cholecystitis $(7,21)$. In our patients who had an acute calcular cholecystitis, the gallbladder histology revealed gangrenous cholecystitis (20.4\%) and $79.6 \%$ had simple cholecystitis. There were a higher bilirubin level and high peripheral leukocyte count in gangrenous cholecystitis patients than simple cholecystitis patients, thus leucocytosis and hyperbilirubinemia were associated with more severe gangrenous cholecystitis(6).

There is a possibility that small stones passed through the duct during biliary colic resulting in biochemical liver function abnormalities. Our results are against this proposal. Firstly, ERCP is so far the most reliable and widely applicable imaging procedure to evaluate the common bile duct. Secondly, small stones less than $0.5 \mathrm{~cm}$ that can pass the duct may induce pancreatitis that is excluded in our patients to reduce this possible confounding factor. Finally, the mildly elevated to normal alkaline phosphatase levels argue against transient stone passage as a cause of the hepatocellular injury $(8,9$, and 22).

It is likely that most bile duct stones pass spontaneously, especially after pancreatitis, biliary colic and cholecystitis but less commonly after jaundice (22).

Our study had some limitations. Firstly, it is a retrospective study in which we performed study only on patients with cholecystitis and it is better that we perform study on general population for better assessment of prediction of liver enzymes in calcular cholecystitis. Secondly, we performed our results in one clinical centre, thus multicenter study and analysis in separated age and sex group were recommended for next studies.

In conclusion, our study showed that the abnormal biochemical liver function test of almost all patients resolved rapidly and spontaneously after cholecystectomy and indicates that there is an acute hepatocellular injury in symptomatic gallstones with cholecystitis in the absence of common bile duct stones and this injury is mild and transient.

\section{REFERENCES}

1. Aydin C, Altaca G, Berber I, Tekin K, Kara M, Titiz I. Prognostic parameters for the prediction of acute gangrenous cholecystitis. J Hepatobiliary pancreat surg. 2000; 13: 155-159.

2. Cameron IC, Chadwick C, Phillips J, Johnson AG. Acute cholecystitis-room for improvement? Ann R Coll Engl., 2000; 84: 10-13.

3. Chang CC, Wang SS. Acute abdominal pain in the elderly. Int. J. Gerontol. 2007; (1): 77-82.

4. Chen CH, Yang PM, Huang GT, Lee HS, Sung JL, Sheu JC. Estimation of seroprevalence of hepatitis B virus and hepatitis $\mathrm{C}$ virus in Taiwan from a large scale survey of free hepatitis screening participants. J. Formos. Med Assoc. 2007; 106: 148-155.

5. Chen W C, Wen HC, Ching CL, Cheng HC, Tsarg EW, Shou CS. Acute transient hepatocellular injury in cholelithiasis and cholecystitis withou evidence of choledocholithiasis. World J. Gastroenterol. 2009; 15 (30): 37883792.

6. Fagan SP, Awad SS, Rahwan K, Hira K, Aoki N, Itani KH, Berger DH. Prognostic factors for the development of gangrenous cholecystitis. Am j surg 2003; 168 5): 481-485.

7. Feher G, Lengyel G, Bla-zovics A. Oxidative stress in the liver and biliary tract diseases. Scand J Gastroenterol. Suppl 1998; 228: 38-46.

8. Fernandez M, Csendes A, Yarmuch J, Diaz H, Silva J. Management of common bile duct stones: The state of the art in 2000. Int surg. 2003; 88(3): 159-163.

9. Freitas ML, Bell RL, Duffy AJ. Choledocholithiasis: evolving standards for diagnosis and management. World J Gastroenterol 2006; 82: 12(20) 31623167.

10. Froom P. Froom J. Elevated liver enzymes in a symptomatic patients. N. Engl. J. Med. 2000; 100: 295-298. Iranica 201 1; 49(10):663-666

11. Geraghty JM, Goldin RD. Liver changes associated with cholecystitis. J. Clin. Pathol. 1994; 47(5):457-460.

12. Habib L, Mirza MR, Ali Channa M, Wasty WH. Role of liver function tests in symptomatic cholelithiasis. J. Ayub. Med. Coll. Abbottabad.2009; 21(2): 117 119.

13. Henry JB. Clinical diagnosis and management by laboratory methods, 17th ed. WB Saunders Company, Philadelphia, 2001; 217-250. Iranica 2011; 49(10):663-666.

14. Kurzweil SM, Shapiro MJ, Andrus CH, Wittgen CM, Herrmann VM, Kamnski DL. Hyperbilirubinemia without CBD abnormalities and hyperamylasemia without pancreatitis in patients with gallbladder disease. Arch. Surg.1994; 128(8): 829-833.

15. Menezes N, Marson LP, Debeaux AC, Muir IM, Auld CD. Prospective analysis of a scoring system to predict choledocholithiasis. Br. J. Surg. 2000; 87: $1167-$ 1181.

16. Mohammad Z, Saeed K, Mohsen A. Mohammed HM. Role of liver function enzymes in diagnosis of choledocholithiasis in biliary colic patients. Acta Medica Iranica 201 1; 49(10):663-666.

17. Mohan H. Textbook of pathology, 4th edition Jaypee Publisher, Delhi 2002; 84: $10-13$. 
18. Nathwani RA, Kumar SR, Reynolds TB, Kaplowitz N. Marked elevation in serum transaminases: an atypical presentation of choledocholithiasis. Am J Gastroenterol. 2005; 100: 295-298.

19. Padda MS, Singh SJ, Tang SJ, Rocky DC. Liver function test patterns in patients with acute calculus cholecystitis and/or choledocholithiasis. Aliment Pharmacol. Ther. 2009; 29(9): 1011-8.

20. Peng WK, Sheikh Z, Paterson BS, Nixon SJ. Role of liver function tests in predicting CBD stones in acute calculus cholecystitis. Br J Surg 2005; 92: 12417.

21. Periera LJC, Jakobs R, Busnello JV, Benz C, Blaya C, Riemann JF. The role of serum liver enzymes in the diagnosis of choledocholithiasis. Hepatogastroenterology 2000; 47(36): 1522-1525.

22. Tranter SE, Thompson MH. Spontaneous passage of bile duct stones: frequency of occurrence and relation to clinical presentation. Ann R Coll Surg Engl. 2003; 85(3): 174-177

23. Thapa PB, Maharjan DK, Suwal B, Byanjankar B, Singh DR. Serum Gammaglutamyl transpeptidase and alkaline phosphatase in acute cholecystitis. J. Nepal Health Res Counc 2010, 8(17): 78-81. 